\title{
Transforaminal Selective Epidural Block for Treating Dorsalgia due to Lumbar Compression Fracture
}

\author{
Farid Yudoyono', Dong Ah Shin ${ }^{2 \otimes}$ \\ 'Departement of Neurosurgery, Hasan Sadikin Hospital, Faculty of Medicine, University of Padjadjaran, Bandung, Jawa Barat, Indonesia \\ ${ }^{2}$ Departement of Neurosurgery, Yonsei University College of Medicine, Seoul, Korea
}

\begin{abstract}
Dorsalgia is the usual presentation of lumbar compression fracture. Bulging periosteum, unstable vertebrae, and narrowed neural foramen may cause dorsalgia and radicular pain. The transforaminal route to the lumbar epidural space for steroid injection has gained rapid and widespread acceptance for the treatment of pain. To report the effectiveness of transforaminal selective epidural block (TFSEB) using $2 \%$ lidocaine and $4 \mathrm{mg}$ dexamethasone. A 52-years-old woman visited our clinic with severe back pain. X-ray showed compression fracture at the level of L1. TFSEB was performed using $5 \mathrm{~mL}$ of $2 \%$ lidocaine and $5 \mathrm{~mL}$ of $4 \mathrm{mg}$ dexamethasone, output measurement using visual analog scale (VAS) and Oswestry disability index (ODI) scores. The intensity of pain was significantly reduced with functional improvement by $50 \%$ until postoperative 6 months post-therapy. TFSEB may be a useful and safe treatment for relieving dorsalgia in a patient with lumbar compression fracture. A prospective series will be followed to evaluate its true efficacy on lumbar compression fracture.
\end{abstract}

Key Words: Compression fracture; Back pain; Lumbar vertebra.

هCorresponding author: Dong Ah Shin, Department of Neurosurgery, Yonsei University College of Medicine, 50-1 Yonsei-ro, Seodaemun-gu, Seoul 03722, Korea. Tel: 82-2-2228-2150, Fax: 82-2-393-9979,E-mail: shindongah@me.com

\section{INTRODUCTION}

An estimated 1.5 million spinal compression fractures occur annualy in the US, spinal compression fractures affect many individuals worldwide. An elderly populations and $25 \%$ of postmenopausal women are affected by a spinal compression fracture during their lifetime. They are potential to cause significant morbidity and disability causing incapacitating back pain for months. The prevalence of this condition increases with age, reaching $40 \%$ by age 80.3 Population studies have shown that the annual incidence of spinal compression fracture is 10.7 per 1000 women and 5.7 per 1000 men and also men older than age 65 years are also at increased risk of compression fractures ${ }^{1,6,10,13}$.

Spinal compression fracture can be classified in three categories : wedge, biconcave, and crush. Wedge fractures are the most common, accounting for more than $50 \%$ of all spinal compression fracture. A previous study using cadaver reported that the anterior compression fracture of the vertebral body increased spinal stress in the posterior structure of the spine including facet joint. Kim et al. reported that concurrent facet joint pain was observed in $88 \%$ of the patients due to body weight load caused by vertebral body compression fracture, and that dull pain with the unclear boundary along the rib and significant discomfort during wake up ${ }^{12)}$.

Transforaminal epidural steroid Blocks (TFESB) is frequently performed to improve the symptoms of radiculopathy and low back pain which are usually observed in patients with spinal stenosis or herniated intervertebral discs ${ }^{3)}$. This procedures is a useful for lumbar radiculopathy and the advantage of delivering highly concentrated medication to the poterior epidural space makes many pain physicians prefer the TFESB technique over an interlaminar or caudal approach.

Here we report a case of compression fracture which was conservatively managed with TFSEB with literature reviews

\section{CASE REPORT}

A 52-years-old woman complained dorsalgia caused by lumbar compression fracture with. From plain X-ray we found compression fracture of the first lumbar vertebrae. The TFESBs were performed under flouroscopy guidance with a usual steril manner. The patient was monitored with ECG and pulse oximetry. 


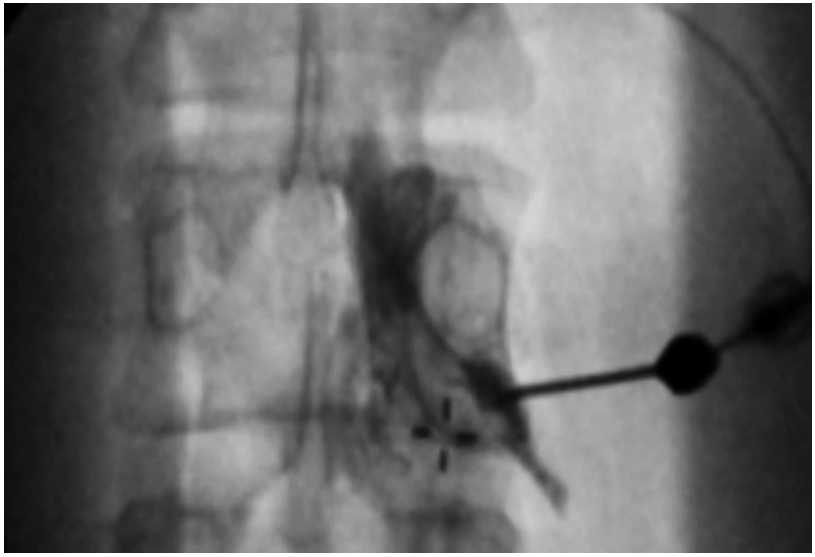

Fig. 1. Contrast injection for detection foraminal location by C-Arm.

The skin was anesthetized with $1 \%$ lidocaine without epinephrine. A 3.5-inch 22-gauge needle was introduced inferior to the pars interarticularis and into the intervertebral foramen using a retroneural approach. Using biplanar visualization, the needle was advanced into the "safe triangle" inferior to the pedicle and supero-lateral to the exiting spinal nerve. A $1 \mathrm{~mL}$ of contrast material (Omnipaque 300, Amersham Health, Princeton, NJ) was injected to confirm epidural flow and to avoid intravascular, intradural, or soft-tissue infiltration.

After confirmation a correct needle position, the combined injectates of a $5 \mathrm{~mL}$ of $2 \%$ lidocaine and $5 \mathrm{~mL}$ of dexamethasone $4 \mathrm{mg}$ was administered (Fig. 1).

Pain was significantly reduced from VAS 9 to VAS 1 immediately following TFSEB and functional status increased by more than $50 \%$ at 3 and 6 months post-procedure.

\section{DISCUSSION}

Vertebroplasty had been the popular treatment for lumbar compression fracture. However its long-term role has been questioned significantly. While vertebroplasty has been abandoned by many physicians, there is no effective way to relieve the significant dorslagia due to compression fracture. TFSEB has been used to treat intractable chronic pain that is not responsive to conservative management, and has been shown to have excellent clinical efficacy. TFSEB provides neural blockade to anaesthetise the target nerve root for diagnostic purposes, and interrupts nociceptive input and self-sustaining activity of the neurons. The technique, however, does not alter the ultimate need for surgery $y^{4,5,7,9,11}$. Consequently, the application of an adequate concentration of steroids or other solution to the appropriate target area could improve outcomes.

The transforaminal approach is a selective injection aimed at a specific level of lesion and is always done under fluoroscopic guidance. Then foraminae are the small lateral openings which the nerve roots traverse to exit the spinal canal. The benefits of then transforaminal approach, when performed by an experienced clinician, include decreased risk for dural puncture with delivery of smaller volumes of steroid to the appropriate site of considered pathology ${ }^{3,10)}$.

Compression fractures of the thoracolumbar spine have a flexion compression mechanism of injury. This mechanism usually involves the first column (anterior longitudinal ligament and anterior half of the vertebral body). Dorsalgia is the main symptom, neurologic deficits tend to be quite infrequent, because such a fracture does not involve retropulsion of bone fragments into the vertebral $\mathrm{canal}^{8)}$.

There are several limitations of the present study. First, this study was a case report. Second, this study limited in vertebral compression fracture only. Hence, improvements in clinical outcomes after TFSEB could not be distinguished from the natural course of disc herniation progression. Third, limited distribution of subjects according to level and type of compression fracture and disc herniation was not optimal for achieving the objectives of this study.

Despite these limitations, we gleaned important clinical insights. We initially hypothesized that the efficacy of TFSEB would differ according to the type of disc herniation or Pfirrmann grade of disease. We also hypothesized that extrusion and sequestration would be worse predictors of a favorable TFSEB outcome.

This study indicates that TFSEB is a potentially suitable treatment for patients with single level compression fracture who do not respond to conservative treatment, there by negating the need for lumbar surgery.

\section{CONCLUSION}

TFSEB may be a useful and safe treatment for relieving dorsalgia in a patient with lumbar compression fracture. A prospective series will be followed to evaluate its true efficacy on lumbar compression fracture.

\section{REFERENCES}

1. Alexandru D, So W : Evaluation and management of vertebral compression fractures. Perm J 16 : 46-51, 2012

2. Collighan N, Gupta S : Epidural steroids. Continuing Education in Anaesthesia, Critical Care \& Pain $10: 1-5,2010$

3. de Souza MF, Kraychete DC: The analgesic effect of intravenous lidocaine in the treatment of chronic pain : a literature review. Rev Bras Reumatol 54: 386-392, 2014

4. Furman MB, Lee TS, Mehta A, Simon JI, Cano WG : Contrast flow selectivity during transforaminal lumbosacral epidural steroid injections. Pain Physician $11: 855-861,2008$

5. Hong JH, Jung S, Chang $\mathrm{H}$ : Whitacre needle reduces the incidence of intravascular uptake in lumbar transforaminal epidural steroid injections. Pain Physician 18 : 325-331, 2015

6. Ji GY, Oh CH, Moon B, Choi SH, Shin DA, Yoon YS, et al. : Efficacy of Percutaneous Epidural Neuroplasty Does Not Correlate with Dural Sac Cross-Sectional Area in Single Level Disc Disease. Yonsei Med J 56 : 691 697, 2015

7. Koh WU, Choi SS, Park SY, Joo EY, Kim SH, Lee JD, et al. : Transforaminal hypertonic saline for the treatment of lumbar lateral canal stenosis : a double-blinded, randomized, active-control trial. Pain Physician 16 : 197 211,2013

8. Kosharskyy B, Almonte W, Shaparin N, Pappagallo M, Smith H : Intrave- 
nous infusions in chronic pain management. Pain Physician 16 : 231249, 2013

9. Leung SM, Chau WW, Law SW, Fung KY : Clinical value of transforaminal epidural steroid injection in lumbar radiculopathy. Hong Kong Med J $21: 394-400,2015$

10. Oh CH, Ji GY, Cho PG, Cho WS, Shin DA, Kim KN, et al. : The catheter tip position and effects of percutaneous epidural neuroplasty in patients with lumbar disc disease during 6-months of follow-up. Pain Physician 17 : E599-E608, 2014

11. Park $\mathrm{CH}$ : Comparison of morphine and tramadol in transforaminal epi- dural injections for lumbar radicular pain. Korean J Pain 26 : 265-269, 2013

12. Park KD, Jee H, Nam PS, Cho SK, Kim HS, Park Y, et al. : Effect of Medial branch block in chronic facet joint pain for osteoporotic compression fracture : one year retrospective study. Ann Rehabil Med 37 : 191-201, 2013

13. Tackla RD, Keller JT, Ernst RJ, Farley CW, Bohinski RJ : Conus medullaris syndrome after epidural steroid injection : case report. International Journal of Spine Surgery $6: 29-33,2012$ 